\title{
LVI. Adjustment of the Kelvin bridge
}

\section{Rollo Appleyard}

To cite this article: Rollo Appleyard (1896) LVI. Adjustment of the Kelvin bridge, Philosophical Magazine Series 5, 41:253, 506-507, DOI: 10.1080/14786449608620877

To link to this article: http://dx.doi.org/10.1080/14786449608620877

$$
\text { 曲 Published online: } 08 \text { May } 2009 .
$$

Submit your article to this journal 준

LII Article views: 3

Q View related articles $\asymp$ 


\section{$\left[\begin{array}{ll}506 & ]\end{array}\right.$ \\ LVI. Adjustment of the Kelvin Bridge. By Rollo Áppleyard*.}

TN a recent paper by Mr. J. H. Reevest an alternative method of adjusting the ratios of the resistances in the Kelvin bridge was described; the following remarks may be regarded as a note upon that paper.

The measurement of a resistance by the arrangement adopted by Mr. Reeves involves two operations. It may be shown, however, that for certain purposes the two adjustments can be combined mechanically, and balance effected by a single test.

Fig. 1.

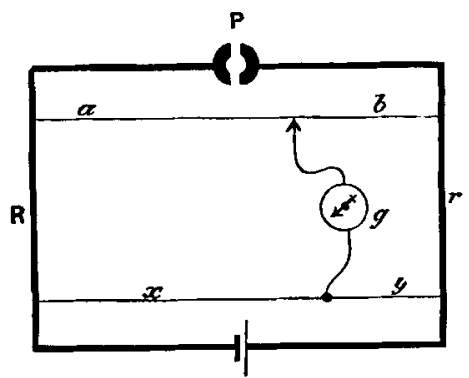

Consider the conductors $\mathrm{R}, r, a, b, x$, and $y$ in fig. 1 . It is required to compare $R$ with $r$. In the accepted form of the Kelvin bridge $a, b, x$, and $y$ have fixed values, such that $a y=b x$, and balance is obtained by the one operation of varying $\mathrm{R}$ or $r$. Mr. Reeres prefers to keep $\mathrm{R}$ and $r$ fixed ; and, consequently, he has first to find provisional values of $a$, $b, x$, and $y$ such that $a y \bumpeq b x$; and then to balance again, using these values, to find $\mathrm{R}: r$; with the plug, this time, inserted at $\mathrm{P}$.

Fig. 2.

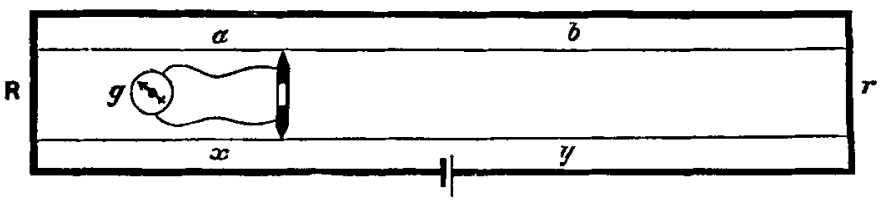

But fig. 1 suggests that $a+b$, and $x+y$, or convenient parts of them, may each be formed into a slide-wire, and that these two slide-wires may be placed parallel to ono

* Communicated by the Physical Society : read April 24, 1896.

† Supra, p. 414. 
Effect of Wave Form on the Alternate Current Arc. 507

another, with a double sliding-contact between them, as shown in fig. 2. Then, in whatever position the slider may be, the fundamental ratio $a y=b x$ is always maintained, and the first condition of the Kelvin bridge is mechanically fulfilled. The one adjustment consists in moving the double slider along the bridge until there is no deflexion of the galvanometer at $g$; in which case

$$
\frac{a}{b}=\frac{x}{y}=\frac{\mathrm{R}}{\gamma^{*}}
$$

Since writing the above, I have referred to the original paper of Lord Kelvin (Proc. Roy. Soc. vol. xi. p. 313, 1861), and find that he proposes the use of parallel slide-wires for his auxiliary conductors; I have no doubt he had in view some such apparatus as that which I have here suggested. A Kelvin bridge with a single slide-wire was used by Matthiessen and Hockin in their differential method; it is described by Clerk-Maxwell in ' Elec. and Mag.' vol. i. p. 406 (1873).

LVII. The Effect of Wave Form on the Alternate Current Arc. By Julius Frite, 1851 Exhibition Scholar*.

$\mathrm{T}^{\mathrm{N}}$ the paper by Dr. Fleming and Mr. Petavel, recently read before the Physical Society, on the Alternate Current Arct, I think too little attention was paid to the wave form of the alternate current used.

It is known that if the are is allowed to exert a preponderating influence at all on the alternate current circuit, it alters the wave form of both the current and the P.D. in a very marked degree.

As an illustration of the change produced in the wave form by the character of the external circuit, I give some curves for alternate current arcs taken from a paper which I read before the Manchester Literary and Philosophical Society in March 1894.

Here is shown, first the E.M.F. curve of the machine on open circuit, which is rather more peaked than a sine curve and involves the third harmonic largely. Next is shown the curve obtained under the same conditions, but with an arc lamp taking 10 amperes at 40 volts joined direct to the machine.

The lag recorded is due to the self-induction of the machine,

* Communicated by the Physical Society : read April 24, 1896.

$\dagger$ Supra, p. 315. 